\title{
Outcomes and prognostic factors for postsurgical pulmonary vein stenosis in the current era
}

David Kalfa, MD, PhD, ${ }^{a}$ Emre Belli, MD, ${ }^{\mathrm{b}}$ Emile Bacha, MD, ${ }^{\mathrm{a}}$ Virginie Lambert, MD, PhD, ${ }^{\mathrm{b}, \mathrm{c}}$

Duccio di Carlo, MD, ${ }^{\mathrm{d}}$ Martin Kostolny, MD, ${ }^{\mathrm{e}}$ Matej Nosal, MD, ${ }^{\mathrm{f}}$ Jurgen Horer, MD, PhD, ${ }^{\mathrm{g}}$ Jukka Salminen, MD,${ }^{\mathrm{h}}$ Jean Rubay, MD, PhD,${ }^{\mathrm{i}}$ Illya Yemets, MD ${ }^{\mathrm{j}}$ Mark Hazekamp, MD, ${ }^{\mathrm{k}}$ Bohdan Maruszewski, MD, ${ }^{\mathrm{l}}$ George Sarris, MD ${ }^{\mathrm{m}}$ Hakan Berggren, MD,${ }^{\mathrm{n}}$ Tjark Ebels, MD, Onur Baser, $\mathrm{PhD},{ }^{\mathrm{p}}$ François Lacour-Gayet, $\mathrm{MD},{ }^{\mathrm{q}}$ and the European Congenital Heart Surgeons Association

\section{ABSTRACT}

Background: The optimal management and prognostic factors of postsurgical pulmonary vein stenosis remain controversial. We sought to determine current postsurgical pulmonary vein stenosis outcomes and prognostic factors in a multicentric study in the current era.

Methods: Seventy-five patients with postsurgical pulmonary vein stenosis who underwent 103 procedures in 14 European/North American centers (20002012) were included retrospectively. A specific pulmonary vein stenosis severity score was developed on the basis of the assessment of each pulmonary vein. End points were death, pulmonary vein reintervention, and restenosis. A univariate and multivariate risk analysis was performed.

Results: Some $76 \%$ of postsurgical pulmonary vein stenosis occurred after repair of a total anomalous pulmonary venous return. Sutureless repair was used in 42 of 103 procedures $(41 \%)$, patch veinoplasty was used in 28 procedures $(27 \%)$, and endarterectomy was used in 16 procedures $(16 \%)$. Overall pulmonary vein restenosis, reintervention, and mortality occurred in 56\% $(n=58 / 103), 49 \%(n=50 / 103)$, and $27 \%(\mathrm{n}=20 / 75)$, respectively. Sutureless repair was associated with less restenosis $(40 \%$ vs $67 \% ; P=.007)$ and less reintervention $(31 \%$ vs $61 \% ; P=.003)$. Mortality after sutureless repair $(20 \% ; 7 / 35)$ tends to be lower than after nonsutureless repair $(33 \% ; 13 / 40)(P=.22)$. A high postoperative residual pulmonary vein stenosis score at the time of hospital discharge was an independent risk factor for restenosis (hazard ratio $[\mathrm{HR}], 1.55 ; P<10^{-4}$ ), reintervention (HR, 1.33; $P<10^{-4}$ ), and mortality (HR, 1.37; $P<10^{-4}$ ). The sutureless technique was an independent protective factor against restenosis $(\mathrm{HR}, 0.27 ; P=.006)$.

Conclusions: Postsurgical pulmonary vein stenosis still has a guarded prognosis in the current era. The sutureless technique is an independent protective factor against restenosis. The severity of the residual disease evaluated by a new severity score is an independent risk factor for poor outcomes regardless of surgical technique. (J Thorac Cardiovasc Surg 2018;156:278-86)

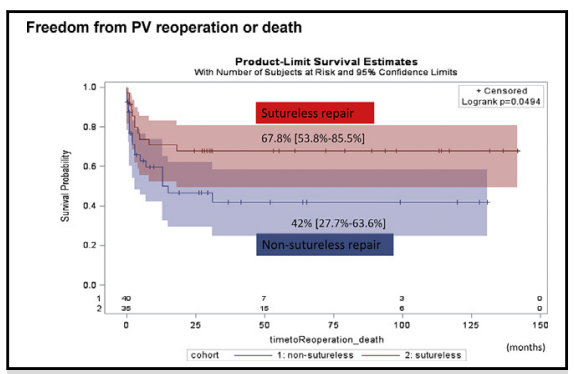

Stratified reoperation-free survival in patients with acquired PVS.

\section{Central Message}

In patients with postsurgical PVS, the use of nonsutureless techniques and the severity of the residual disease are independent risk factors for worse outcomes.

\section{Perspective}

PSPVS still has a guarded prognosis in the current era. The sutureless technique used for acquired PSPVS is an independent protective factor against PV restenosis. The severity of the residual disease evaluated by a new severity score is an independent risk factor for poor outcomes regardless of surgical technique.

See Editorial Commentary page 287

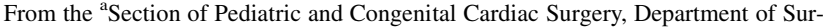
gery, Morgan Stanley Children's Hospital of New York-Presbyterian, and ${ }^{\mathrm{P} C e n t e r}$ for Innovation and Outcomes Research, Columbia University, New York, NY; ${ }^{\mathrm{b}}$ Department of Pediatric Cardiac Surgery, Marie Lannelongue Hospital, Paris, France; ${ }^{\mathrm{c}}$ Department of Cardiology, Institut Mutualiste Montsouris, Paris, France; ${ }^{\mathrm{d}}$ Department of Pediatric Cardiac Surgery, Ospedale Pediatrico Bambino Gesù, Roma, Italy; ${ }^{\mathrm{D}}$ Department of Pediatric Cardiac Surgery, Great Ormond Street Hospital, London, United Kingdom; ${ }^{\mathrm{f}}$ Department of Pediatric Cardiac Surgery, National Institute of Cardio-Vascular Diseases - Childrens Heart Center, Bratislava, Slovakia; ${ }^{\mathrm{g}}$ Department of Pediatric Cardiac Surgery, German Heart Center, Clinic of Cardiovascular Surgery, Munich, Germany; ${ }^{\mathrm{h}}$ Department of Pediatric Cardiac Surgery, Hospital for Children and Adolescents, University of Helsinki, Helsinki, Finland; i Department of Pediatric Cardiac Surgery, Saint-Luc Hospital, Brussels, Belgium; ${ }^{\mathrm{j}}$ Department of Pediatric Cardiac Surgery, Ukrainian Childrens Cardiac Center, Kyiv, Ukraine; ${ }^{\mathrm{k}}$ Department of Pediatric Cardiac Surgery, Leiden University Medical Center, Leiden, The Netherlands; ${ }^{1}$ Department of Pediatric Cardiac Surgery, Children's Memorial Health Institute, Warsaw, Poland; ${ }^{\mathrm{m}}$ Department of
}

Pediatric Cardiac Surgery, Athens Heart Surgery Institute, Mitera Pediatric and Hygeia Hospital, Athens, Greece; ' Department of Pediatric Cardiac Surgery, Children's Heart Center, The Queen Silvia Children's Hospital, Goteborg, Sweden; ${ }^{\circ}$ Department of Pediatric Cardiac Surgery, University Medical Center Groningen, Groningen, The Netherlands; ${ }^{9}$ Department of Pediatric Cardiac Surgery, Royal Hospital, Muscat, Oman; and European Congenital Heart Surgeons Association. Read at the 97th Annual Meeting of The American Association for Thoracic Surgery, Boston, Massachusetts, April 29-May 3, 2017.

Received for publication April 29, 2017; revisions received Feb 7, 2018; accepted for publication Feb 15, 2018; available ahead of print March 22, 2018.

Address for reprints: David Kalfa, MD, PhD, Morgan Stanley Children's Hospital of New York-Presbyterian, Columbia University Medical Center, Department of Pediatric Cardiac Surgery, 3959 Broadway, New York, NY 10032 (E-mail: dk2757@ cumc.columbia.edu). $0022-5223 / \$ 36.00$

Copyright (c 2018 by The American Association for Thoracic Surgery https://doi.org/10.1016/j.jtcvs.2018.02.038 


\section{Abbreviations and Acronyms \\ GLM = generalized linear model \\ $\mathrm{HR}=$ hazard ratio \\ $\mathrm{IQR}=$ interquartile range \\ MRI = magnetic resonance imaging \\ $\mathrm{PV}=$ pulmonary vein \\ PVS = pulmonary vein stenosis \\ PSPVS $=$ postsurgical pulmonary vein stenosis \\ $\mathrm{TAPVR}=$ total anomalous pulmonary venous return}

Scanning this QR code will take you

to the article title page.

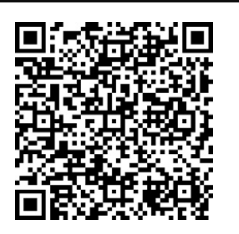

Postsurgical pulmonary vein stenosis (PSPVS) is defined as pulmonary vein stenosis (PVS) occurring secondarily after a cardiac surgical procedure. PSPVS can occur after many types of cardiac surgery and is particularly common after repair of total anomalous pulmonary venous drainage, affecting $10 \%$ to $17 \%$ of patients. ${ }^{1,2}$ Pulmonary vein (PV) restenosis, reintervention, and mortality rates after surgical repair of PSPVS remain high. The concept of the sutureless technique for PVS repair avoiding the suture of the veins themselves was introduced in the mid-1990s. s $^{3-6}$ This technique was presented as real progress in some early reports, ${ }^{7-9}$ while appearing disappointing in the more recent ones, ${ }^{10-16}$ especially in the series focusing on patients with congenital PVS. ${ }^{11-13,15,17}$ The outcomes of this technique in the specific population of PSPVS and risk factors for poor outcomes are still controversial because series are often limited and heterogeneous. We sought to determine current outcomes after surgical repair for PSPVS and prognostic factors in a large multicentric study focusing on PSPVS treated in the current era.

\section{PATIENTS AND METHODS \\ Patient Inclusion and Data Collection}

Patients included in this study are those in whom PSPVS developed, as defined earlier, and who then underwent at least 1 surgical repair of PSPVS in a participating institution between January 1, 2000, and January 1, 2013. Fourteen European or North American institutions were enrolled in this retrospective study. We did not include (1) patients with primary PVS, (2) patients with normal PVs at birth who then developed a PVS without any prior surgery, and (3) patients with PSPVS who were not treated $(n=1)$ or who were treated by a percutaneous procedure or a pneumonectomy as an initial procedure $(\mathrm{n}=3)$. The collection of data regarding patient characteristics, PVS characteristics, types of surgical procedures, and outcomes was approved by each hospital's local committee on clinical investigation and was performed according to a common and uniform database to ensure consistency. Hospital records were reviewed in each center, and follow-up data were obtained by contacting the treating cardiologists. Studied end points were (1) PSPVS-related death, (2) persistence or recurrence of moderate (echographic mean gradient $5-7 \mathrm{~mm} \mathrm{Hg}$ ) or severe (echographic mean gradient $>7 \mathrm{~mm} \mathrm{Hg}$ ) stenosis of at least 1 vein, and (3) PV reintervention or PSPVS-related death. Severe pulmonary hypertension was defined in this study as pulmonary artery pressure greater than $3 / 4$ systemic pressure.

\section{Severity Score}

A specific PVS severity score was previously developed by our group. ${ }^{16}$ Briefly, the assessment of each vein was based on echocardiography before each procedure in all cases, strengthened by angiography, computed tomography (CT) scan and magnetic resonance imaging (MRI) in $52 \%, 9 \%$, and $7 \%$ of cases, respectively. This score is based on (1) the degree of the stenosis evaluated by the echographic pressure gradient measured at the venoatrial junction, (2) the focal/diffuse aspect of the stenosis evaluated by the combined imaging modalities mentioned above, and (3) the unilateral/bilateral feature of the disease. The absence of stenosis was defined by the absence of PV narrowing, a biphasic blood flow, and a mean echo gradient less than $2 \mathrm{~mm} \mathrm{Hg}$. Mild, moderate, and severe stenosis were defined by a mean echo gradient of 2 to $4 \mathrm{~mm} \mathrm{Hg}, 5$ to $7 \mathrm{~mm} \mathrm{Hg}$, and greater than $7 \mathrm{~mm} \mathrm{Hg}$, respectively. The stenosis was described as "focal" when affecting a very short length of the PV and associated with upstream dilatation of the PV. The stenosis was "diffuse" when affecting a significant length of the PV with no upstream dilation of the PV. The assignment of numbers for each PV (range, 0-4) to the score (range, 0-18) is described in Table 1. All imaging reports were completed by experienced cardiologists in each center, independently of the outcome of the PV procedure. There were no missing data. PVS scores were then established by a single observer, independently of the outcome of the PV procedure. The postoperative PVS score was defined at the time of hospital discharge.

\section{Surgery}

The different types of surgical procedures are described in the "Results" section. Of note, in the resection-type sutureless technique, the PV pathologic tissue was totally resected along with a part of the left atrial wall. When an endoveinectomy was performed, stenosed veins were opened longitudinally to go beyond the level of the stenosis (as proximally as possible), and the surgeon excised the fibrotic tissue in the area.

\section{Data Analysis}

Data analysis was performed with SAS software (version 9.4, SAS Institute Inc, Cary, NC). Data are expressed as median with interquartile range (IQR) or mean \pm standard deviation. The comparison of percentages was achieved with the chi-square test or Fisher exact test for qualitative variables. Comparison of means and medians was performed using the Student $t$ test or Mann-Whitney $U$ test. Actuarial freedom curves from mortality, $\mathrm{PV}$ recurrence, and PV reintervention/mortality were analyzed according to the Kaplan-Meier estimates with $95 \%$ confidence intervals. A univariate analysis of time-related end points was achieved with the log-rank test and the univariate Cox model for continuous variables. The multivariate Cox model was used for the multivariable analysis of time-related end points. Variables that were found to be associated with the 3 studied end points with a $P$ value less than .1 in the univariate analysis or that had clinical relevance were included in the logistic models. The covariates in the multivariate Cox analysis include age, gender, weight, postoperative PSV severity score, and sutureless procedure. Because the postoperative PVS severity score was a time-varying covariate during the observation time, it was added into the Cox model as a time-dependent variable. Calibration of the logistic model was assessed using the Hosmer-Lemeshow goodnessof-fit test to evaluate the discrepancy between observed and expected values. Hazard ratios (HRs) were expressed with $95 \%$ confidence intervals. 
TABLE 1. Specific severity score for pulmonary vein stenosis

\begin{tabular}{ll}
\hline 1) Each PV is graded from 0 to 4 \\
0 & No stenosis \\
1 & Mild stenosis-focal \\
1.5 & Mild stenosis-diffuse \\
2 & Moderate stenosis-focal \\
2.5 & Moderate stenosis-diffuse \\
3 & Severe stenosis-focal \\
3.5 & Severe stenosis-diffuse \\
4 & Atresia/occlusion \\
2) PVS severity score $=$ sum of these scores +2 if bilateral disease \\
(possible range, $0-18)$
\end{tabular}

$P V$, Pulmonary vein; $P V S$, pulmonary vein stenosis.

The linearity in the logit assumption and proportional hazards assumption was assessed and met. Given the continuous response variable of postoperative PVS severity score, we used the generalized linear model (GLM) with negative binomial distribution to estimate if the choice of surgical procedure (sutureless vs nonsutureless) resulted in a lower PVS severity score at the time of hospital discharge. The covariates in the GLM include age, gender, weight, preoperative PSV severity score greater than 8.5 , diffuse aspect of PVS, single ventricle, bilateral disease, dispersion, and sutureless procedure. All the tests were 2-sided. Analysis of variance was used to compare PVS scores before and after the repair. Predictive accuracy for the obtained PVS score value was assessed by calculating the area under the receiver operating characteristics curve, and model calibrations and fit were assessed with Hosmer-Lemeshow goodness-of-fit statistics.

\section{RESULTS}

\section{Demographic, Anatomic, and Surgical Characteristics}

A total of 75 patients with PSPVS underwent 103 procedures. Demographic, anatomic, and surgical characteristics are presented in Table 2. The mean age at the procedure was 5 months (IQR, 0-184). Twenty-six patients had a single ventricle physiology. Sixty-two percent of patients had a bilateral disease, and half of the patients had a diffuse stenosis of at least $1 \mathrm{PV}$. The median preoperative severity score was 8.0 (IQR, 5.0-12.0). A PVS score greater than 8.5 and greater than 9 had the best predictive accuracy for PV restenosis (area under the curve 0.63) and PV reintervention or death (area under the curve 0.61), respectively. There were no significant differences in the preoperative severity of the disease between the sutureless and nonsutureless groups (Table 2). The PV repair followed a previous repair of total anomalous pulmonary venous return (TAPVR) in 58 patients $(77 \%)$ and a previous repair of a non-TAPVR cardiac surgery in 17 patients $(23 \%)$.

The types of sutureless procedures $(n=42)$ and nonsutureless procedures $(n=61)$ are described in Table 2. PV plasty was performed in 51 procedures using a patch of autologous pericardium $(n=24)$, polytetrafluoroethylene $(n=9)$, or appendage tissue $(n=3)$, and using no patch in 15 patients. Median patient follow-up was 29 months (IQR, 5-72 months).

\section{Surgical Outcomes}

A global overview of the outcomes is presented in Figure 1 and Table 3 (univariable analysis). Overall mortality, PV reintervention/mortality, and PV restenosis occurred in $27 \%(\mathrm{n}=20 / 75), 49 \%(\mathrm{n}=50 / 103)$, and $56 \%(\mathrm{n}=58 /$ 103), respectively. The descriptive analysis shows significant difference of postoperative PVS score at discharge between the sutureless procedure and the nonsutureless procedure (mean 3.04 vs $5.87, P=.0048$; median 0.00 vs $5.00, P=.0049)$. The postoperative severity score at discharge, the severity score at last follow-up, and the postoperative improvement of the PVS score at discharge after sutureless procedures were all significantly better compared with after nonsutureless procedures $(P=.0048, P=.0025$, and $P=.02$ ) (Table 3). A plot showing the values of the PVS severity score before surgery, after surgery at discharge, and at last follow-up for each patient is presented in Figure 2, B. Sutureless repair was associated with less restenosis $(40 \%$ vs $67 \% ; P=.007)$ and less reintervention $(31 \%$ vs $61 \% ; P=.003)$ compared with nonsutureless procedures at last follow-up (Table 3 ). The mortality rate after sutureless repair $(20 \% ; 7 / 35)$ tended to be lower than after nonsutureless repair $(33 \% ; 13 / 40)$ but was not statistically significant $(P=.22)$ (Table 3). Kaplan-Meier actuarial curves for the 3 end points are presented in Figures 2 and 3. Freedom from mortality, reintervention, and restenosis at 5 years of follow-up were $71 \% \pm 10 \%, 55 \% \pm 11 \%$, and $56 \% \pm 11 \%$, respectively (Figure 3). Restenosis occurred in the first postoperative year in the majority of cases, with a median delay of 3.3 months (range, 1 month to 5 years). Reintervention-free survival at 5 years was significantly lower in patients who had a nonsutureless repair ( $42 \%$ vs $68 \% ; P=.049$ ) (Figure $2, A$ ) and postoperative pulmonary hypertension $(11 \%$ vs $83 \% ; P=.0001)$.

Results of the univariate analysis are shown in Table 4 . Factors significantly associated with PV restenosis, reintervention, or mortality are low weight at surgery, female gender, use of a nonsutureless procedure, and a high postoperative severity score at the time of hospital discharge (all $P<.05$ ).

The GLM multivariate analysis showed that the choice of sutureless procedure reduced the postoperative PVS severity score by 0.4346 and $P=.2249$, conditional on the demographic and clinical characteristic (age, gender, weight, preoperative PSV severity score $>8.5$, diffuse aspect of PVS, single ventricle, bilateral disease, and dispersion).

Multivariate analysis (Table 4) showed that a high postoperative residual PVS score at the time of hospital discharge was an independent risk factor for restenosis (HR, 1.55; $P<10^{-4}$ ), reintervention (HR, 1.33; $P<10^{-4}$ ) and mortality (HR, $1.37 ; P<10^{-4}$ ). The sutureless technique was an independent protective factor against restenosis (HR, $0.27 ; P=.006)$. 
TABLE 2. Demographic, anatomic, and surgical characteristics

\begin{tabular}{|c|c|c|c|c|}
\hline & $\begin{array}{c}\text { All PSPVS } \\
\text { patients: } \mathbf{N}(\%) \\
\text { patients: } \mathbf{n}=\mathbf{7 5} \\
\text { procedure: } \mathbf{n}=\mathbf{1 0 3}\end{array}$ & $\begin{array}{c}\text { Sutureless } \\
\text { procedure: } N(\%) \\
\text { patients: } n=35 \\
\text { procedures: } n=42\end{array}$ & $\begin{array}{c}\text { Nonsutureless } \\
\text { procedure: } N(\%) \\
\text { patients: } n=\mathbf{4 0} \\
\text { procedures: } \mathbf{n}=\mathbf{6 1}\end{array}$ & $\begin{array}{c}\text { Comparison sutureless } \\
\text { vs nonsutureless } \\
\text { initial procedures } \\
(P \text { value })\end{array}$ \\
\hline \multicolumn{5}{|l|}{ Demographic and anatomic characteristics } \\
\hline Male gender & $42 / 75(56 \%)$ & $22 / 35(63 \%)$ & $20 / 40(50 \%)$ & $P=.26$ \\
\hline \multicolumn{5}{|l|}{ Age at procedure $(\mathrm{mo})$} \\
\hline Mean & $13 \pm 28$ & $9 \pm 12$ & $18 \pm 37$ & $P=.19$ \\
\hline Age $<6$ mo at initial procedure & $42(56 \%)$ & $24(69 \%)$ & $18(45 \%)$ & $P=.04^{*}$ \\
\hline Weight at procedure $(\mathrm{kg})$ & Mean: $7 \pm 9$ & Mean: $6 \pm 6$ & Mean: $9 \pm 10$ & $P=.15$ \\
\hline Prematurity (<35 wk) & $4 / 75(5 \%)$ & $3 / 35(9 \%)$ & $1 / 40(3 \%)$ & $P=.32$ \\
\hline Median birth weight $(\mathrm{kg})$ & $3.2(2.8-3.5)$ & $3.2(2.7-3.6)$ & $3.2(2.9-3.5)$ & $P=.95$ \\
\hline Genetic syndrome & $13 / 75(17 \%)$ & $4 / 35(11 \%)$ & $9 / 40(22 \%)$ & $P=.36$ \\
\hline Associated lesions & $54(72 \%)$ & $24(68 \%)$ & $30(75 \%)$ & $P=.61$ \\
\hline Single ventricle & 26 & 5 & 21 & $P=.09$ \\
\hline Atrial septal defect & 25 & 11 & 14 & \\
\hline Ventricular septal defect & 8 & 4 & 4 & \\
\hline Transposition of the great arteries & 4 & 1 & 3 & \\
\hline $\begin{array}{l}\text { Preoperative pulmonary hypertension at } \\
\text { initial presentation: PA pressure }>3 / 4 \\
\text { systemic pressure }\end{array}$ & $22 / 75(29 \%)$ & $12 / 35(34 \%)$ & $10 / 40(25 \%)$ & $P=.38$ \\
\hline \multicolumn{5}{|l|}{ Preoperative No. of obstructed PVs } \\
\hline 1 & $13(13 \%)$ & $6(14 \%)$ & $7(11 \%)$ & \\
\hline 2 & $28(27 \%)$ & $14(33 \%)$ & $14(23 \%)$ & $P=.64$ \\
\hline 3 & $12(11 \%)$ & $4(9 \%)$ & $8(11 \%)$ & \\
\hline 4 & $50(48 \%)$ & $18(43 \%)$ & $32(52 \%)$ & \\
\hline Bilateral disease & $64 / 103(62 \%)$ & $25 / 42(60 \%)$ & $39 / 61(64 \%)$ & $P=.65$ \\
\hline $\begin{array}{l}\text { At least } 1 \mathrm{PV} \text { with a diffuse stenosis } \\
\text { (no upstream PV dilation) }\end{array}$ & $52 / 103(50 \%)$ & $17 / 42(40 \%)$ & $21 / 61(34 \%)$ & $P=.53$ \\
\hline \multicolumn{5}{|l|}{ Preoperative severity score } \\
\hline Median (IQR) & $8.0(5.0-12.0)$ & $7.5(5.0-11.0)$ & $9.0(5.0-12.0)$ & $P=.17$ \\
\hline \multicolumn{5}{|l|}{ Characteristics of the surgical procedures } \\
\hline TAPVR repair & $58 / 75(77 \%)$ & $31 / 35(88 \%)$ & $27 / 40(67 \%)$ & \\
\hline After other type of cardiac surgery & $17 / 75(23 \%)$ & $4 / 35(12 \%)$ & $13 / 40(33 \%)$ & $P=.64$ \\
\hline Type of surgery & & $\begin{array}{l}\text { - incision type: } 20(47 \%) \\
\text { - resection type: } 14(33 \%) \\
\text { - incision + resection: } \\
8(19 \%)\end{array}$ & $\begin{array}{l}\text { - excision of fibrotic tissue } \\
\text { (endoveinectomy): } \\
10(16 \%) \\
\text { - PV plasty: } 21(34 \%) \\
\text { - endoveinectomy }+ \text { PV } \\
\text { plasty: } 30(52 \%)\end{array}$ & \\
\hline Redo procedures & $28 / 103(27 \%)$ & $7 / 42(16 \%)$ & $21 / 61(34 \%)$ & $P=.04^{*}$ \\
\hline Circulatory arrest & $39 / 103(38 \%)$ & $23 / 42(55 \%)$ & $16 / 61(26 \%)$ & $P=.008^{*}$ \\
\hline
\end{tabular}

$P S P V S$, Postsurgical pulmonary vein stenosis; $P A$, pulmonary artery; $P V$, pulmonary vein; $I Q R$, interquartile range; $P V S$, pulmonary vein stenosis; TAPVR, total abnormal pulmonary venous return. $* P<.05$.

\section{DISCUSSION}

To our knowledge, this study is the largest series of patients with PSPVS published in the literature. This study shows that PSPVS still has a guarded prognosis in the current era with high rates of restenosis, PV reintervention, and mortality. The sutureless technique used for PSPVS is associated with a lower risk of PV restenosis and reintervention and may tend to reduce the risk of mortality. The sutureless technique is an independent protective factor against restenosis. The severity of the residual disease evaluated by a new severity score is an independent risk factor for poor outcomes regardless of surgical technique.

Reported recurrence, reintervention, and mortality rates after repair of PSPVS remain high in the literature. ${ }^{10-12,14,15,18-22}$ Toronto's group and Boston's group recently reported in 2015 an actuarial survival of $60 \%$ to $64 \%$ between 2 and 5 years after surgery despite a large experience in PVS treatment. ${ }^{14,20}$ Our multicentric series focusing on patients treated for PSPVS in the current era 


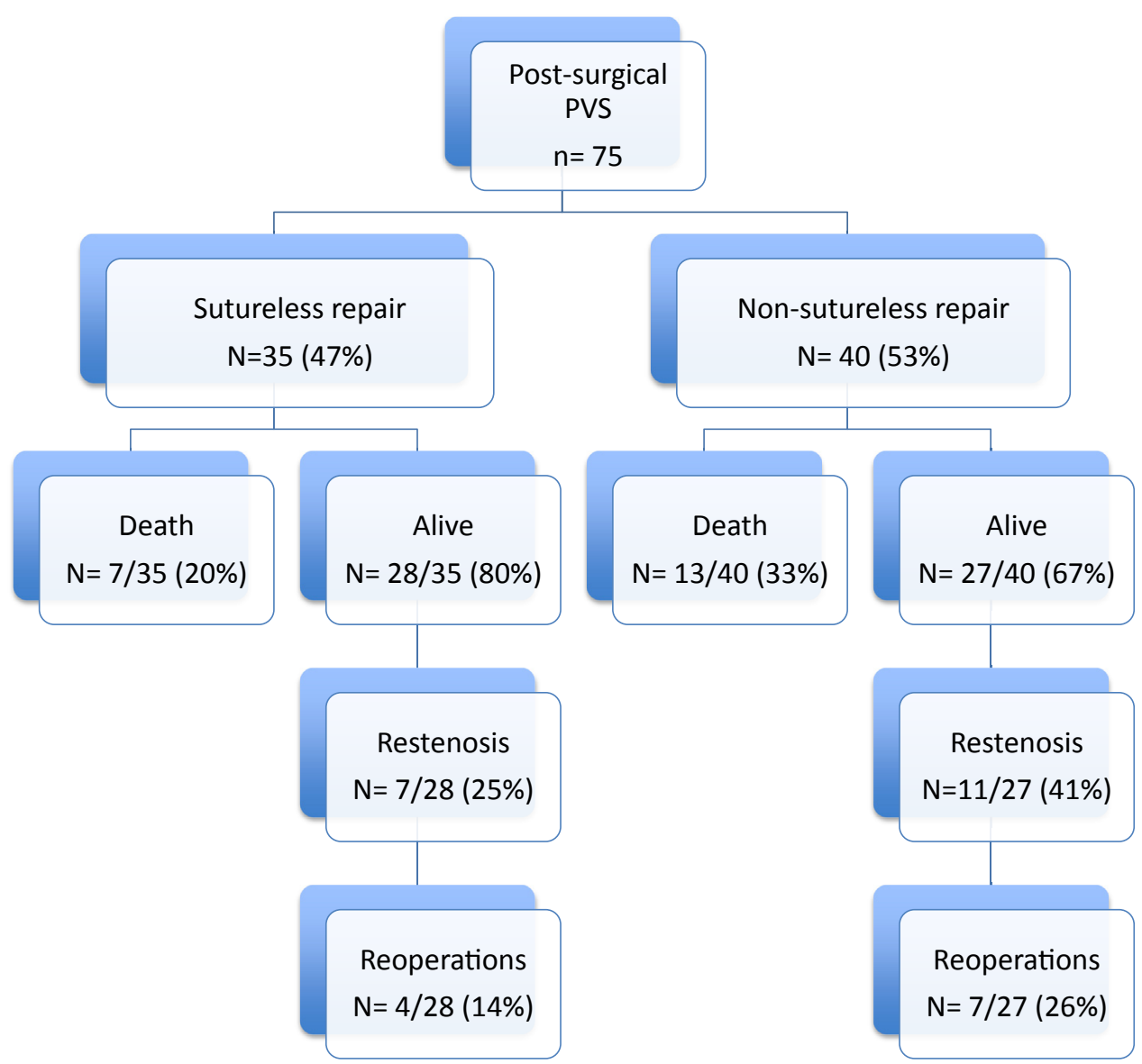

FIGURE 1. Global overview of the outcomes of the patients with PSPVS. PVS, Pulmonary vein stenosis.

confirms such disappointing results, with actuarial freedom from mortality, reintervention, and restenosis at 5 years of follow-up at $71 \% \pm 10 \%, 55 \% \pm 11 \%$, and $56 \% \pm 11 \%$, respectively. Restenosis occurred in the first year in the majority of cases, with a median delay of
3.3 months, as previously shown by other groups in series of both congenital and PSPVS. ${ }^{11}$

Patient-related factors associated with poor outcomes still remain controversial in the literature because of the small sample size of previous studies. ${ }^{10,14,19,23}$ Of note,

TABLE 3. Overall outcomes

\begin{tabular}{lcccc}
\hline & $\begin{array}{c}\text { All PSPVS } \\
\text { procedures: } \mathbf{N}(\%) \\
\mathbf{N}=\mathbf{1 0 3}\end{array}$ & $\begin{array}{c}\text { Sutureless } \\
\text { procedures: } \mathbf{N}(\%) \\
\mathbf{n}=\mathbf{4 2}\end{array}$ & $\begin{array}{c}\text { Nonsutureless } \\
\text { procedures: } \mathbf{N}(\%) \\
\mathbf{n}=\mathbf{6 1}\end{array}$ & $\begin{array}{c}\text { Comparison sutureless vs } \\
\text { nonsutureless procedures } \\
(\boldsymbol{P} \text { value })\end{array}$ \\
\hline Severity score at discharge. Median (IQR) & $3.5(0-9)$ & $0(0-6)$ & $5(0-10.75)$ & $P=.005 *$ \\
Severity score at last follow-up & $5.5(0-11.5)$ & $2(0-7)$ & $8(2-12)$ & $P=.0025 *$ \\
median (IQR) & Mean: $-47 \% \pm 49 \%$ & Mean: $-60 \% \pm 51 \%$ & Mean: $-38 \% \pm 46 \%$ & $P=.02 *$ \\
Percentage of score improvement & $17(17 \%)$ & $6(14 \%)$ & $11(18 \%)$ & $P=.61$ \\
RV/LV pressure ratio $>75 \%$ at last follow-up & $58(56 \%)$ & $17(40 \%)$ & $41(67 \%)$ & $P=.007 *$ \\
Recurrence/persistence of PVS & $28(27 \%)$ & $5(12 \%)$ & $23(38 \%)$ & $P=.004 *$ \\
PV reintervention & $50(49 \%)$ & $13(31 \%)$ & $37(61 \%)$ & $P=.003 *$ \\
PV reintervention or mortality & $20(27 \%)$ & $7(20 \%)$ & $13(33 \%)$ & $P=.22$ \\
Mortality & &
\end{tabular}

Medians and IQRs were compared via the Mann-Whitney $U$ test. Mean and standard deviation were compared via $t$ test. $\mathrm{N}$ and percentage were compared via chi-square test. $P S P V S$, Postsurgical pulmonary vein stenosis; $I Q R$, interquartile range; $R V$, right ventricle; $L V$, left ventricle; $P V S$, pulmonary vein stenosis; $P V$, pulmonary vein. *Statistically significant $(P<.05)$. 


\section{Freedom from PV reintervention or death}

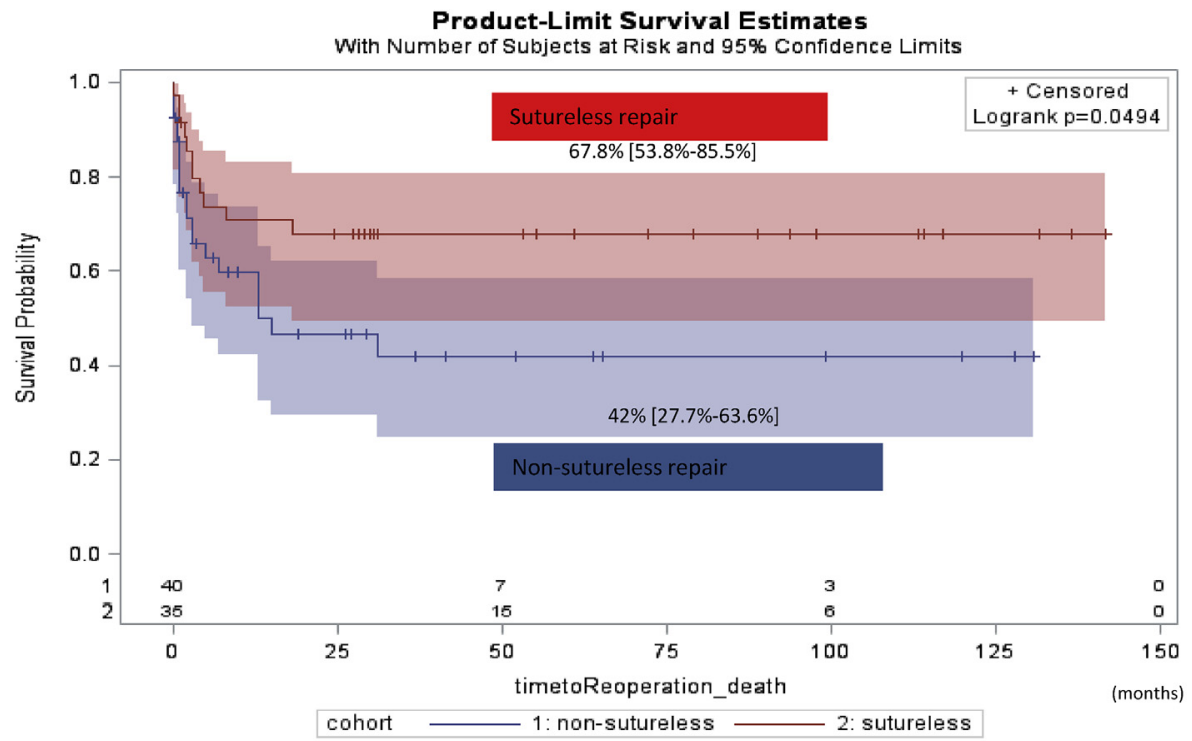

A

cohort 1 : non-sutureless 2 : sutureless

cohort

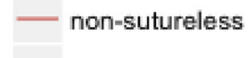

sutureless

B

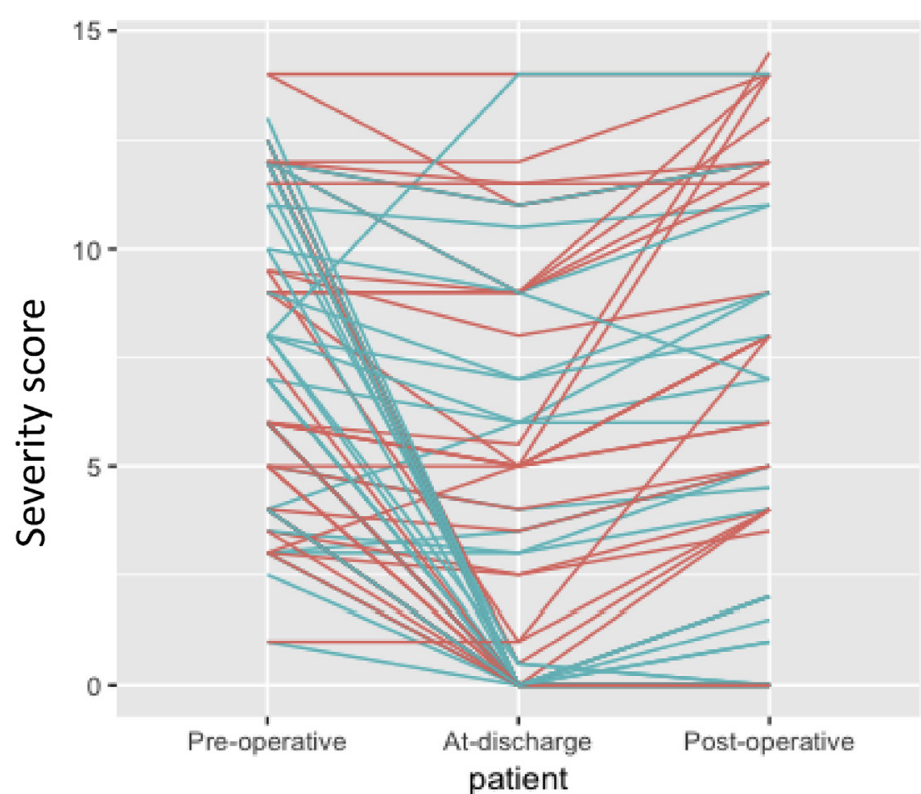

FIGURE 2. A, Kaplan-Meier actuarial curves for PV reintervention or death, stratified by the type of repair. B, Plot showing the values of the PVS severity score before surgery, after surgery at discharge, and at last follow-up for each patient. $P V$, Pulmonary vein.

young age at procedure, prematurity, single ventricle anatomy, genetic anomalies, and heterotaxy syndrome are not associated with poor outcomes in our series. Overall, these patient-related demographic and genetic factors, which are common risk factors for patients with other severe congenital heart diseases, seem to have little or no impact in this specific population of PSPVS. This could be explained by the major role played by the intrinsic severity of the PVS disease, which can mask the potential impact of other factors. Of note, female gender was associated with poorer outcomes, which will need to be confirmed by other studies.

The intrinsic severity of the disease before or after the procedure appears to be the most decisive factor determining final outcomes, not only in congenital PVS ${ }^{11,12,16}$ but also in PSPVS, as shown in the present series. A high postoperative PVS score at the time of hospital discharge is an independent risk factor of PV restenosis, 


\section{Freedom \\ from death}

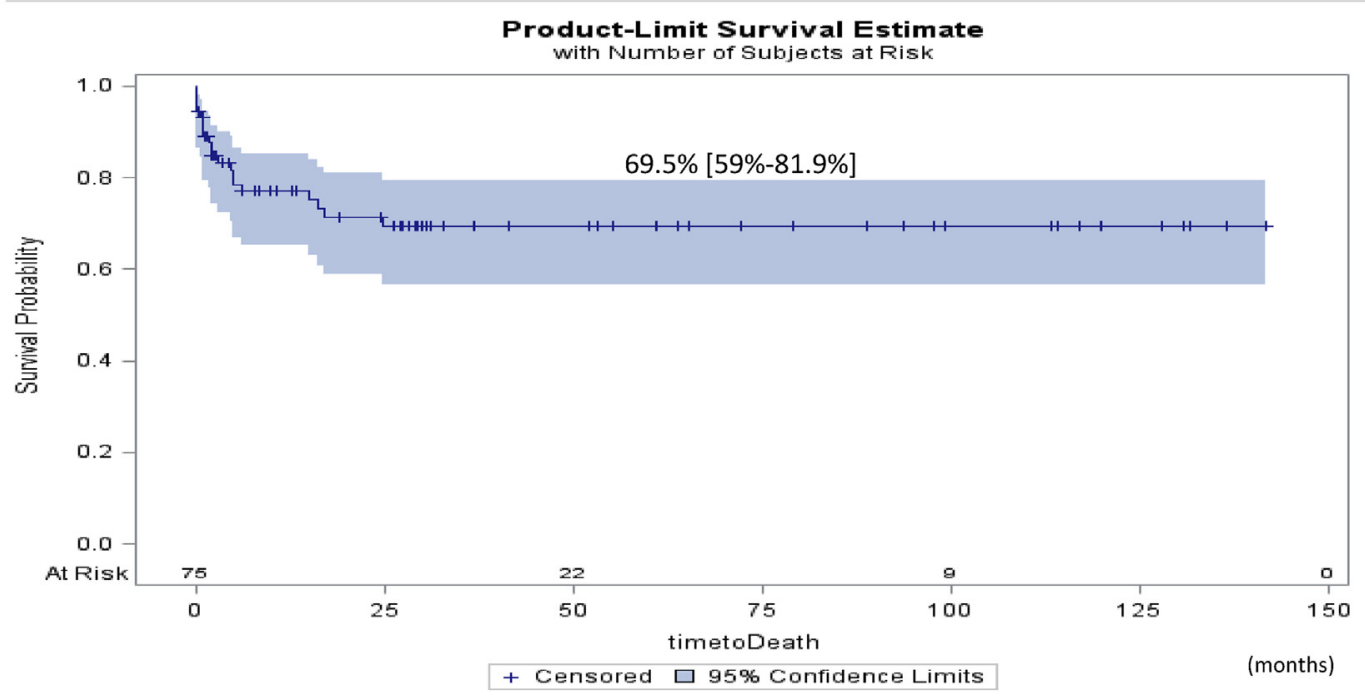

A

\section{Freedom from PV restenosis}

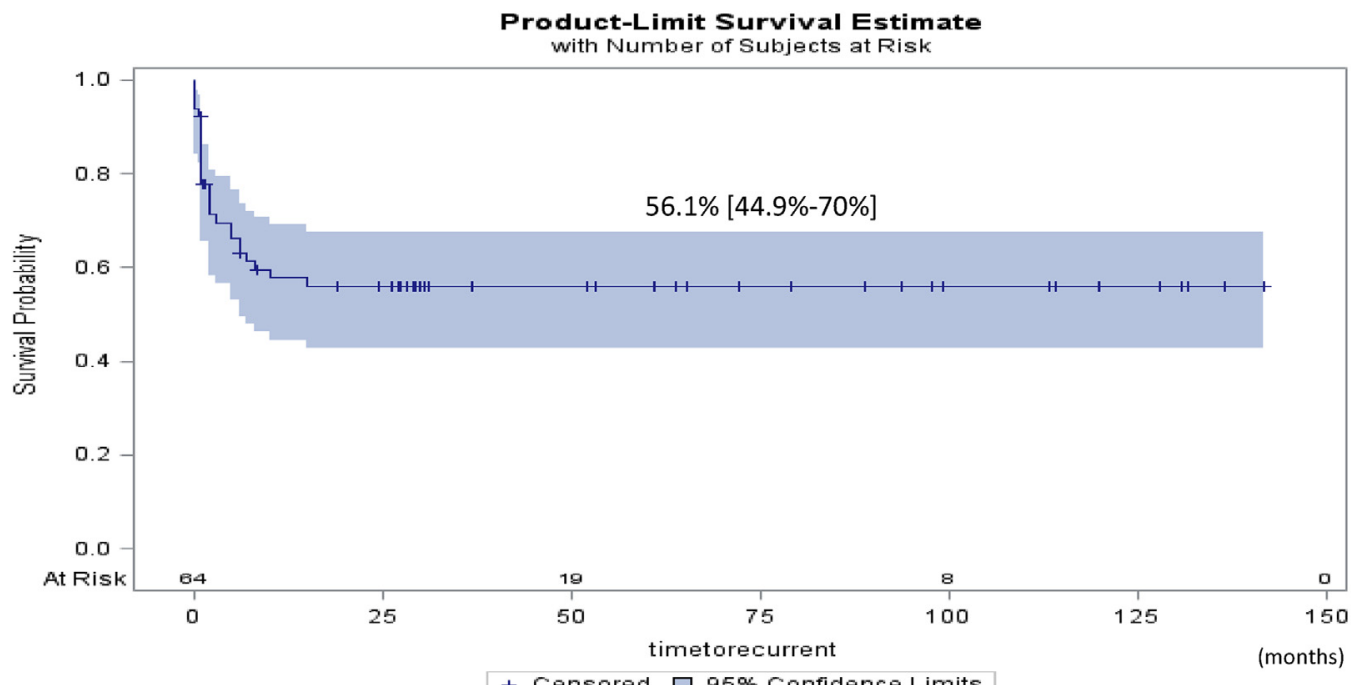

B

\section{Freedom from}

PV

reintervention or death

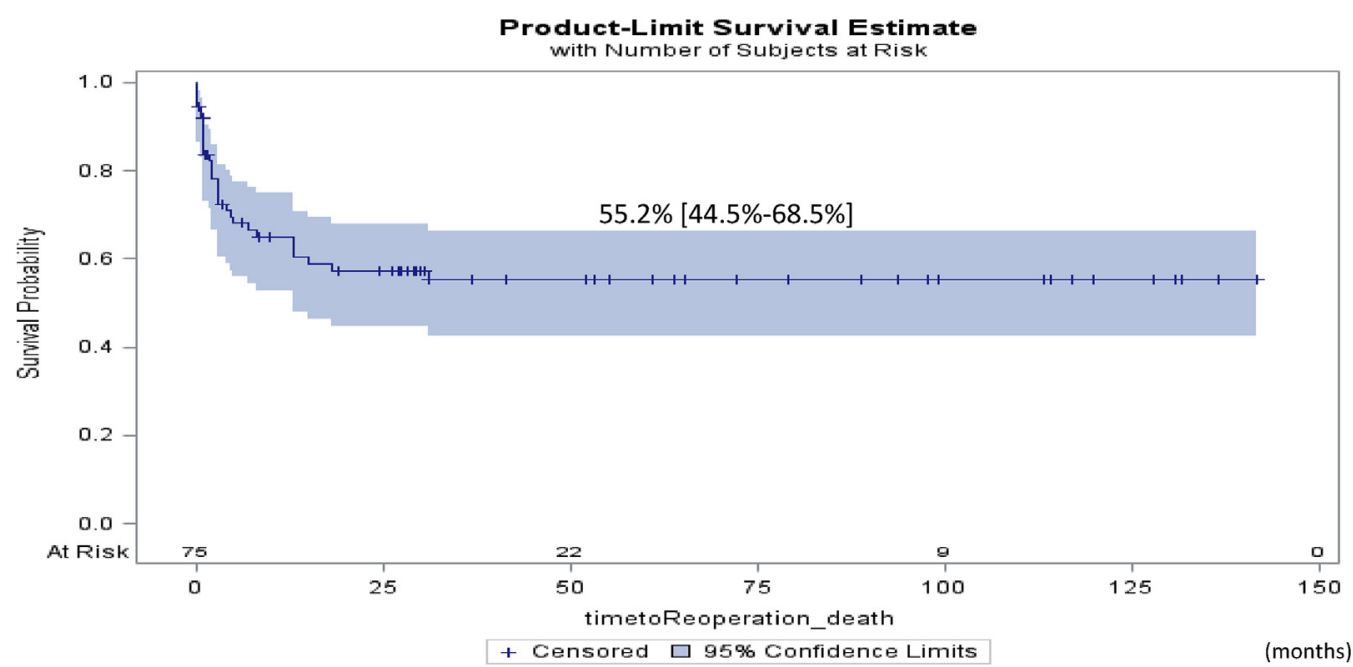

C

FIGURE 3. Kaplan-Meier actuarial curves for death (A), PV restenosis (B), and PV reintervention or death (C). PV, Pulmonary vein. 
TABLE 4. Results of the univariate and multivariate Cox model on the 75 patients

\begin{tabular}{|c|c|c|c|}
\hline & PV restenosis & PV reintervention or death & Mortality \\
\hline \multicolumn{4}{|l|}{ Univariate analysis } \\
\hline Weight & $\mathrm{HR}, 0.91 ; \mathrm{SE}=0.05 P=.12$ & $\mathrm{HR}, 0.91 ; \mathrm{SE}=0.5 ; P=.09$ & $\mathrm{HR}, 0.73 ; \mathrm{SE}=0.14 ; P=.03 \dagger$ \\
\hline Female gender & $\mathrm{HR}, 2.94 ; \mathrm{SE}=0.39 ; P=.006^{*}$ & $\mathrm{HR}, 2.29 ; \mathrm{SE}=0.36 ; P=.02 *$ & $\mathrm{HR}, 2.82 ; \mathrm{SE}=0.47 ; P=.03 *$ \\
\hline Preoperative severity score $>8.5$ & $\mathrm{HR}, 1.7 ; \mathrm{SE}=0.39 ; P=.15$ & $\mathrm{HR}, 1.06 ; \mathrm{SE}=0.37 ; P=.88$ & $\mathrm{HR}, 1.92 ; \mathrm{SE}=0.45 ; P=.14$ \\
\hline Diffuse aspect of PVS & $\mathrm{HR}, 1.7 ; \mathrm{SE}=0.39 ; P=.16$ & $\mathrm{HR}, 1.51 ; \mathrm{SE}=0.36 ; P=.25$ & $\mathrm{HR}, 1.68 ; \mathrm{SE}=0.45 ; P=.25$ \\
\hline Single ventricle & $\mathrm{HR}, 1.51 ; \mathrm{SE}=0.41 ; P=.31$ & $\mathrm{HR}, 1.30 ; \mathrm{SE}=0.41 ; P=.52$ & $\mathrm{HR}, 1.19 ; \mathrm{SE}=0.52 ; P=.72$ \\
\hline Bilateral disease & $\begin{array}{c}\mathrm{HR}, 2.21 ; \mathrm{SE}=0.44 \\
P=.07\end{array}$ & $\mathrm{HR}, 1.19 ; \mathrm{SE}=0.37 ; P=.64$ & $\mathrm{HR}, 1.36 ; \mathrm{SE}=0.47 ; P=.51$ \\
\hline Sutureless procedure & $\mathrm{HR}, 0.34 ; \mathrm{SE}=0.44 ; P=.01 \dagger$ & $\mathrm{HR}, 0.49 ; \mathrm{SE}=0.38 ; P=.05 \dagger$ & $\mathrm{HR}, 0.51 ; \mathrm{SE}=0.47 ; P=.15$ \\
\hline $\begin{array}{l}\text { Postoperative severity score at the } \\
\text { time of hospital discharge }\end{array}$ & $\mathrm{HR}, 1.49 ; \mathrm{SE}=0.06 ; P<.001^{*}$ & $\mathrm{HR}, 1.36 ; \mathrm{SE}=0.05 ; P<.001^{*}$ & $\mathrm{HR}, 1.40 ; \mathrm{SE}=0.06 ; P<.001^{*}$ \\
\hline \multicolumn{4}{|l|}{ Multivariate analysis } \\
\hline Sutureless procedure & $\mathrm{HR}, 0.27 ; \mathrm{SE}=0.47 ; P=.006 \dagger$ & $\mathrm{HR}, 0.59 ; \mathrm{SE}=0.39 ; P=.19$ & $\mathrm{HR}, 1.08 ; \mathrm{SE}=0.54 ; P=.89$ \\
\hline $\begin{array}{l}\text { Postoperative severity score at the } \\
\text { time of hospital discharge }\end{array}$ & $\mathrm{HR}, 1.55 ; \mathrm{SE}=0.07 ; P<.001 *$ & $\mathrm{HR}, 1.33 ; \mathrm{SE}=0.05 ; P<.001 *$ & $\mathrm{HR}, 1.37 ; \mathrm{SE}=0.07 ; P<.001$ \\
\hline Female gender & $\mathrm{HR}, 2.33 ; \mathrm{SE}=0.45 ; P=.06$ & $\mathrm{HR}, 1.10 ; \mathrm{SE}=0.40 ; P=.80$ & $\mathrm{HR}, 1.17 ; \mathrm{SE}=0.53 ; P=.76$ \\
\hline Weight & $\mathrm{HR}, 0.99 ; \mathrm{SE}=0.19 ; P=.99$ & $\mathrm{HR}, 0.86 ; \mathrm{SE}=0.20 ; P=.46$ & $\mathrm{HR}, 0.75 ; \mathrm{SE}=0.36 ; P=.43$ \\
\hline Age & $\mathrm{HR}, 0.98 ; \mathrm{SE}=0.05 ; P=.80$ & $\mathrm{HR}, 1.03 ; \mathrm{SE}=0.05 ; P=.59$ & $\mathrm{HR}, 0.99 ; \mathrm{SE}=0.11 ; P=.97$ \\
\hline
\end{tabular}

Results are presented as HR, SE, and $P$ value. $P V$, Pulmonary vein; $H R$, hazard ratio; $S E$, standard error; $P V S$, pulmonary vein stenosis. ${ }^{*}$ Significant $(P<.05)$. $\nmid$ Protective factor.

reintervention, and death. A greater number of stenotic PVs has been shown to be associated with an increased risk of death, especially when there is bilateral involvement in some series of PSPVS. ${ }^{19,24,25}$ The only 5 independent predictors of mortality demonstrated so far in the literature in multivariate analysis (high preoperative PVS score by Viola and colleagues, ${ }^{12}$ involvement of greater than $3 \mathrm{PV}$ and progression to uninvolved PVs by Song and colleagues, ${ }^{11}$ and postoperative high PVS score and pulmonary hypertension 1 month after surgery by Kalfa and colleagues ${ }^{16}$ ) were shown in series focusing on congenital PVS. The multivariable analysis in our series confirms that the severity of the residual disease and the adequacy of the surgical PV decompression at the time of hospital discharge are the main determinants of late outcomes in patients with PSPVS.

The impact of the specific PVS score that our group described for the population of congenital PVS ${ }^{16}$ seems to remain true in the population of PSPVS. The impact of this score emphasizes the major role played by the severity of the residual disease after surgery compared with the score described by the Toronto group. ${ }^{8,12}$ The PVS score used in the present study takes into account the focal/ diffuse aspect of each PVS and the bilateral aspect of the disease. Despite the inherent limitations of echocardiography to assess the PV "upstream" in the lung parenchyma, this score showed a good predictive accuracy for PV restenosis (cutoff >8.5) and reintervention (cutoff $>9$ ).

The sutureless procedure has been based on the concept of reducing trauma to the veins in hopes of reducing any stimulus for regrowth of obstructive tissue. This technique initially led to promising results, ${ }^{3,5,6}$ including improved survival in some series, ${ }^{4,8,9,26,27}$ but most recent series reported disappointing outcomes, ${ }^{10-15,17,25}$ especially in children with primary PVS PV $^{71,12,15,16}$ or those with single ventricle anatomy. ${ }^{26}$ Toronto's group showed that the sutureless technique to repair post-TAPVR PSPVS improved survival and reduced need for reinterventions,, 8 but in contrast has been largely ineffective in the patients with primary PVS. ${ }^{12}$ Although not showing any positive impact of the sutureless repair in our previously published series of patients with congenital PVS ${ }_{1}^{16}$ we demonstrate in the present series focusing on PSPVS that the sutureless technique was associated with a lower risk of PV restenosis and reintervention and may tend to reduce the risk of mortality in this different population of patients (univariate analysis). We also show in the multivariate analysis that the sutureless technique is an independent protective factor against PV restenosis.

\section{Study Limitations}

This study is limited by its retrospective nature, with its inherent risks of selection bias, retrospective suboptimal data collection, and the absence of a fully centralized imaging core laboratory. The multicentric aspect of this study led to a significant heterogeneity of patients and decisionmaking processes regarding imaging and interventions that were not based on protocols. Patients in the nonsutureless group tended to have a higher preoperative PVS severity score and more single ventricle defects. Although these variables were not statistically significant, when taken as a whole in the setting of relatively few outcome events, these differences could account for some of the differences 
between the groups. The operator-dependent aspect of surgical PV procedures could not be taken into account in the multivariate analysis because of the large number of participating institutions and surgeons and the variability of patients enrolled per institution. The PVS-related morbidity and neurodevelopment-related outcomes and quality of life of patients were not assessed in this study. The PVS score described was based on retrospective echocardiographic data, included too sparse data from CT and MRI, and still needs to be validated in a prospective study. Indeed, in this retrospective study, angiography, CT, and MRI were obtained in $52 \%, 9 \%$, and $7 \%$, respectively, before surgery and $24 \%, 14 \%$, and $11 \%$, respectively, after surgery. Overall, $62 \%$ of patients had nonechocardiographic imaging before the procedure and $38 \%$ of patients had imaging after surgery. This nonsystematic use of additional imaging modalities may introduce a bias into the comparison of preoperative and postoperative PVS severity scores. Finally, histologic specimen and genetic studies would have been of major interest to investigate further the mechanisms at work in this complex disease but could not be performed for logistical reasons.

\section{CONCLUSIONS}

Postsurgical PVS still has a guarded prognosis in the current era. The sutureless technique used for acquired PSPVS is an independent protective factor against PV restenosis. The severity of the residual disease evaluated by a new severity score is an independent risk factor for poor outcomes regardless of surgical technique.

\section{Conflict of Interest Statement}

Authors have nothing to disclose with regard to commercial support.

\section{References}

1. Hancock Friesen CL, Zurakowski D, Thiagarajan RR, Forbess JM, del Nido PJ, Mayer JE, et al. Total anomalous pulmonary venous connection: an analysis of current management strategies in a single institution. Ann Thorac Surg. 2005; 79:596-606.

2. Seale AN, Uemura H, Webber SA, Partridge J, Roughton M, Ho SY, et al. Total anomalous pulmonary venous connection: morphology and outcome from an international population-based study. Circulation. 2010;122:2718-26.

3. Lacour-Gayet F, Rey C, Planche C. Pulmonary vein stenosis. Description of a sutureless surgical procedure using the pericardium in situ. Arch Mal Coeur Vaiss. 1996;89:633-6.

4. Caldarone CA, Najm HK, Kadletz M, Smallhorn JF, Freedom RM, Williams WG, et al. Relentless pulmonary vein stenosis after repair of total anomalous pulmonary venous drainage. Ann Thorac Surg. 1998;66:1514-20.

5. Najm HK, Caldarone CA, Smallhorn J, Coles JG. A sutureless technique for the relief of pulmonary vein stenosis with the use of in situ pericardium. $J$ Thorac Cardiovasc Surg. 1998;115:468-70.
6. Lacour-Gayet F. Surgery for pulmonary venous obstruction after repair of total anomalous pulmonary venous return. Semin Thorac Cardiovasc Surg Pediatr Card Surg Annu. 2006;45-50.

7. Devaney EJ, Chang AC, Ohye RG, Bove EL. Management of congenital and acquired pulmonary vein stenosis. Ann Thorac Surg. 2006;81:992-5.

8. Yun TJ, Coles JG, Konstantinov IE, Al-Radi OO, Wald RM, Guerra V, et al. Conventional and sutureless techniques for management of the pulmonary veins: evolution of indications from postrepair pulmonary vein stenosis to primary pulmonary vein anomalies. J Thorac Cardiovasc Surg. 2005;129:167-74.

9. Azakie A, Lavrsen MJ, Johnson NC, Sapru A. Early outcomes of primary sutureless repair of the pulmonary veins. Ann Thorac Surg. 2011;92:666-71.

10. Kanter KR, Kirshbom PM, Kogon BE. Surgical repair of pulmonary venous stenosis: a word of caution. Ann Thorac Surg. 2014;98:1687-91.

11. Song MK, Bae EJ, Jeong SI, Kang IS, Kim NK, Choi JY, et al. Clinical characteristics and prognostic factors of primary pulmonary vein stenosis or atresia in children. Ann Thorac Surg. 2013;95:229-34.

12. Viola N, Alghamdi AA, Perrin DG, Wilson GJ, Coles JG, Caldarone CA. Primary pulmonary vein stenosis: the impact of sutureless repair on survival. J Thorac Cardiovasc Surg. 2011;142:344-50.

13. Charlagorla P, Becerra D, Patel PM, Hoyer M, Darragh RK. Congenital pulmonary vein stenosis: encouraging mid-term outcome. Pediatr Cardiol. 2016;37: 125-30.

14. Quinonez LG, Gauvreau K, Borisuk M, Ireland C, Marshall AM, Mayer JE, et al. Outcomes of surgery for young children with multivessel pulmonary vein stenosis. J Thorac Cardiovasc Surg. 2015;150:911-7.

15. Shi G, Zhu Z, Chen H, Zhang H, Zheng J, Liu J. Surgical repair for primary pulmonary vein stenosis: single-institution, midterm follow-up. J Thorac Cardiovasc Surg. 2015;150:181-8.

16. Kalfa D, Belli E, Bacha E, Lambert V, di Carlo D, Kostolny M, et al. Primary pulmonary vein stenosis: outcomes, risk factors, and severity score in a multicentric study. Ann Thorac Surg. 2017;104:182-9.

17. Holt DB, Moller JH, Larson S, Johnson MC. Primary pulmonary vein stenosis. Am J Cardiol. 2007;99:568-72.

18. Latson LA, Prieto LR. Congenital and acquired pulmonary vein stenosis. Circulation. 2007;115:103-8.

19. Seale AN, Webber SA, Uemura H, Partridge J, Roughton M, Ho SY, et al. Pulmonary vein stenosis: the UK, Ireland and Sweden collaborative study. Heart. 2009;95:1944-9.

20. Lo Rito M, Gazzaz T, Wilder T, Saedi A, Chetan D, Van Arsdell GS, et al. Repair type influences mode of pulmonary vein stenosis in total anomalous pulmonary venous drainage. Ann Thorac Surg. 2015;100:654-62.

21. Lo Rito M, Gazzaz T, Wilder TJ, Vanderlaan RD, Van Arsdell GS, Honjo O, et al. Pulmonary vein stenosis: severity and location predict survival after surgical repair. J Thorac Cardiovasc Surg. 2016;151:657-66.

22. Seale AN, Daubeney PEF. Pulmonary vein stenosis-novel strategies for a challenging and resistant condition? J Thorac Cardiovasc Surg. 2016;151:618-20.

23. Drossner DM, Kim DW, Maher KO, Mahle WT. Pulmonary vein stenosis: prematurity and associated conditions. Pediatrics. 2008;122:e656-61.

24. Seale AN, Uemura H, Webber SA, Partridge J, Roughton M, Ho SY, et al. Total anomalous pulmonary venous connection: outcome of postoperative pulmonary venous obstruction. J Thorac Cardiovasc Surg. 2013;145:1255-62.

25. Breinholt JP, Hawkins JA, Minich LA, Tani LY, Orsmond GS, Ritter S, et al. Pulmonary vein stenosis with normal connection: associated cardiac abnormalities and variable outcome. Ann Thorac Surg. 1999;68:164-8.

26. Devaney EJ, Ohye RG, Bove EL. Pulmonary vein stenosis following repair of total anomalous pulmonary venous connection. Semin Thorac Cardiovasc Surg Pediatr Card Surg Annu. 2006;51-5.

27. Hickey EJ, Caldarone CA. Surgical management of post-repair pulmonary vein stenosis. Semin Thorac Cardiovasc Surg Pediatr Card Surg Annu. 2011;14: $101-8$.

Key Words: congenital heart disease, outcomes, pulmonary vein stenosis, sutureless repair 